The Version of Record of this manuscript has been published and is available in Death Studies

$20^{\text {th }}$ Dec 2019 https://doi.org/10.1080/07481187.2019.1702121

A Pilot Study of a New Bereavement Program for Children: Lionheart Camp for Kids

\author{
Natasha Griffiths ${ }^{1}$ \\ Trevor G. Mazzucchelli ${ }^{1}$ \\ Shelly Skinner ${ }^{2,3}$ \\ Robert T. Kane ${ }^{1}$ \\ Lauren J. Breen ${ }^{1}$
}

${ }^{1}$ School of Psychology, Curtin University, Perth, Western Australia, Australia

${ }^{2}$ Lionheart Camps for Kids, Perth, Western Australia, Australia

${ }^{3}$ Perth Children's Hospital, Perth, Western Australia, Australia

Correspondence concerning this article should be addressed to Dr. Lauren J. Breen, School of Psychology, Curtin University, GPO Box U1987, Perth Western Australia 6845, Australia. Email lauren.breen@curtin.edu.au 


\begin{abstract}
We assessed the acceptability and effectiveness of a new childhood bereavement service known as Lionheart Camp for Kids. Using a pre-post-follow-up design, data pertaining to 12 bereaved children (aged 5-12 years) and their primary caregivers were obtained. Results showed that caregivers reported decreases in children's peer relationship problems, improvements in parental consistency, and reductions in coercive parenting, and there was a trend towards lower self-reported grief by the children. Caregivers were highly satisfied with the program. There is a need for a wait-list or randomized controlled trial over a longer time period to determine the full benefits of the camp.
\end{abstract}

Keywords: bereavement, caregivers, children, death of a parent, family process, pediatrics, support groups 


\section{A Pilot Study of a New Bereavement Program for Children: Lionheart Camp for Kids}

The death of a parent is widely accepted as one of the most distressing and potentially disruptive stressors that can occur for children (Lin, Sandler, Ayers, Wolchik, \& Luecken, 2004), with long-term increased risk of physical illnesses (Tafà, Cerniglia, Cimino, Ballarotto, Marzilli, \& Tambelli, 2018). Similarly, the death of a sibling during childhood is associated with symptoms of post-traumatic stress disorder (PTSD), depression, and prolonged grief disorder (PGD; Morris, Gabert-Quillen, Friebert, Carst, \& Dalahunty, 2016) and long-term cognitive and socio-emotional outcomes (Fletcher, Vidal-Fernandez, \& Wolfe, 2018). Age when bereaved (Christ \& Christ, 2006), developmental stage (Machajewski \& Kronk, 2013), cause of the death (Pfeffer, Karus, Siegel, \& Jiang, 2000), relationship to the deceased (Lin et al., 2004), and relationship with the remaining caregiver (Saldinger, Porterfield, \& Cain, 2004) all shape the way a child responds to bereavement.

There are no routine data collected concerning the incidence of bereavement in childhood. Estimates from the United Kingdom suggest that, by the age of 16 years, $5 \%$ of children are bereaved by the death of a parent (Parsons, 2011) and that the majority has experienced the death of a close relative or friend (Ribbens McCarthy \& Jessop, 2005). In the United States, approximately 1 in 20 children aged up to 15 years will be bereaved by the death of one or both parents (Kirwin \& Hamrin, 2005) and it is estimated that $0.08 \%$ of children will experience a sibling bereavement each year (Hulsey, Hill, Layne, Gaffney, \& Kaplow, 2013), or about $8 \%$ by the age of 25 years (Fletcher, Mailick, Song, \& Wolfe, 2013). These figures do not account for the number of children who lose another close person, such as a friend or grandparent (Owens, 2008). Further, although bereavement in childhood is more common than many people might think, a bereaved child and any siblings are unlikely to know of others in the same situation, which is why bereaved children describe "feeling alone and different" (Aynsley-Green, Penny, \& Richardson, 2012, p. 2).

Most of what is known about the outcomes of childhood bereavement is based upon parental bereavement in childhood. The Harvard Child Bereavement Study was the first comprehensive study of childhood bereavement. Parentally-bereaved children aged 6 to 17 years were matched for age and gender 
to a control group, and followed for two years (Worden \& Silverman, 1996). The study revealed three key findings. First, not all bereaved children needed professional help, but $21 \%$ of the bereaved children accessed professional support in the first two years, whereas only 9-11\% of the control group did. Second, the surviving parent/caregiver's emotional availability, capacity to provide responsive care, and consistent discipline were powerful predictors of the children's adaptation to bereavement. Third, many of the negative consequences associated with the loss of a parent did not appear in the first two years. This finding has implications for when to offer support. Even hospice and palliative care, which provide the most developed bereavement care, generally focus on the first year after the death (American Academy of Pediatrics Section on Hospice and Palliative Medicine and Committee on Hospital Care, 2013; Breen, Aoun, O’Connor, \& Rumbold, 2014). Further, within palliative care, the lack of staff training on childhood bereavement and the limited supports offered that are specific to childhood bereavement has been noted (Owens, 2008).

For children, normative responses to grief include internalizing feelings of sadness, loss, confusion, anger, self-blame, and jealousy of non-bereaved peers and sometimes externalizing behaviors including "acting out" or non-compliance with established rules (Carr, 2015). Bereaved children are more prone to develop symptoms including anxiety, depression, somatic disorders, and PTSD in the years following the death (Brent, Melhem, Donohoe, \& Walker, 2009). Furthermore, researchers have attempted to differentiate between those children experiencing what are considered to be typical responses to grief, and enduring or pathological grief, which has been conceptualized as being either as prolonged or complicated (Melhem, Moritz, Walker, Shear, \& Brent, 2007). In addition, it is common for bereaved children to also experience changes in caregivers, financial means, residence, and school (Aynsley-Green et al., 2012).

Bereavement occurs within a family system (Breen et al., 2019) and it is unsurprising that family factors would directly influence a child's adjustment. Echoing a key finding from the Harvard Child Bereavement Study (Worden \& Silverman, 1996), an analysis of adults' narratives of parental bereavement in childhood showed that surviving parents who were described as maintaining continuity in 
routines and fostering open and honest communication with the surviving child, and who received instrumental and social support from others, were likely to promote better outcomes for their children in adulthood (Ellis, Dowrick, \& Lloyd-Williams, 2013). Further, bereaved mothers' symptoms of PTSD and PGD were associated with surviving children's outcomes, irrespective of the mothers' parenting style (Morris et al., 2016). The same study showed that the effect of fathers' symptoms on the surviving siblings' outcomes was mediated by their parenting style, in that positive parenting behaviors were associated with lower PTSD, depression, and PGD symptoms (Morris et al., 2016). Another study showed that bereaved children reported lower levels of anxiety, depression, and PTSD symptoms when parents engaged in expressive coping, and lower levels of PTSD when parents provided positive reinforcement and supportive communication (Howell, Barrett-Becker, Burnside, Wamser-Nanney, Layne, \& Kaplow, 2016).

Given that bereavement is a significant stressor for bereaved children and their caregivers, and that support is likely to mitigate longer-term deleterious outcomes, there is a need for services to support both. A recent meta-analysis showed that most support programs for parentally-bereaved children aim to support the children and their caregivers; few focus on the children only (Bergman, Axberg, \& Hanson, 2017). The most researched intervention is the Family Bereavement Program, which has shown benefits for children and caregivers in the short- and long-term (Sandler, Tein, Cham, Wolchik, \& Ayers, 2016). Although studies of these support programs were considered to be generally of high quality (Bergman et al., 2017), researchers face two challenges. The first concerns decisions about what to measure-whether the focus is caregiver variables (e.g., caregiver grief, coping, mental health, caregiver discipline, and warmth), child variables (e.g., grief, mental health, coping, and self-esteem), environmental factors (e.g., stressors, school), or a combination. After identifying the constructs of interest, the second challenge is to determine how to measure them. For instance, there are far fewer grief measures for children, especially younger children, and for use in non-clinical samples (Griese, Burns, Farro, Silvern, \& Talmi, 2017).

There are few studies of support programs for bereaved children, especially younger-aged children, and none in Australia (Bergman et al., 2017). A new program known as Lionheart Camp for 
Kids was established to cater to all bereaved families with children aged 5 to 12 years, irrespective of the means of death. Given that the evaluation of childhood bereavement services tends to be limited and piecemeal, conducted by the services themselves, and with self-designed measures (Rolls \& Penny, 2011), there is a need for careful research to determine if bereavement services are effective (Wilson et al., 2017). The purpose of the study was to investigate the acceptability and effectiveness of this bereavement service.

\section{Method}

\section{Design}

We adopted a prospective, longitudinal, pre-post-follow-up design and collected quantitative and qualitative data to provide a comprehensive understanding of the program's impact.

\section{The Program}

Lionheart Camp for Kids (LHCK) provides support to grieving children (aged 5 to 12 years) living in Perth, Western Australia, following the death of a parent, primary caregiver, or sibling. LHCK aims to improve long-term life outcomes for bereaved children and enable them to integrate grief into their lives in an environment that is loving, accepting, compassionate, and bound by safety. The objectives of the camp are to (a) help children and parents understand the process of grief; (b) normalize the grief process for children and increasing their awareness of loss as a natural part of living; (c) help children identify with a spectrum of emotions associated with the death of a family member; (d) share and express emotions in a healthy, constructive way; (e) provide the opportunity to connect with other bereaved children; and (f) strengthen parents' knowledge and skills in how to support their grieving children.

The LHCK camp program was developed to include activities designed by a team of expert staff (i.e., a clinical psychologist, bereavement counsellor, teacher, and social worker) as well as activities in use in other child bereavement programs in Australia (e.g., Wombat's Wish and Camp Magic, both of which operate elsewhere in Australia) and internationally (e.g., Eluna's Camp Erin in the United States). All staff members meet the requirements of their professional regulation bodies, engage in regular 
professional development training, and attend other bereavement camps in Australia for benchmarking and learning purposes.

The first LHCK camp was run over two consecutive days in July, 2017. The camp was facilitated by a team of professionals (two social workers, one teacher, and one psychologist) and trained volunteers (one volunteer for every 4 to 5 children) and involved both separate and collaborative activities for children and their caregivers. On the morning of the first day, LHCK staff attempted to normalize the families' experience, by inviting children to share a photograph of their deceased family member, and lighting a candle in memoriam that burned throughout the day. Structured activities provided in small groups based on children's ages were interspersed with free play and regular breaks. LHCK staff delivered grief psychoeducation to children using developmentally-appropriate activities including sand jars representative of feelings, memory rocks, artwork, and water play. Coping strategies including breathing, relaxation, grounding, and mindfulness techniques were introduced on the second day. On the second day, children were provided the opportunity to ask a guest medical doctor any questions they may have. Concurrently, caregivers were provided psychoeducation about the relationship between developmental stages and children's grief experiences, and staff encouraged modelling of caregivers' sharing feelings and memories with their children. Adaptive coping strategies were discussed, such as repairing ruptures in relationships, and using mistakes as an opportunity for teaching, and communication with the child about grief. Collaborative activities between children and adults included developing a family "Memory Chain" constructed from pre-loss memories, events from the time of the death (such as the funeral), and significant moments since the death in which the family established their new normal.

The foundation program is modified for each camp based on the specific needs of the children attending. For example, if some children have issues with anger or separation anxiety, specific activities are added to address these issues. Additionally, there are certain activities throughout the program where participants are allocated according to the ages of the children and/or specifics of the grief experience (e.g., relationship to the deceased, length of time since the death). However, staff and volunteers have 
confirmed that children have not identified that another child's grief is different from theirs; instead, they identify with the shared experience of someone they love dying.

\section{Participants}

Inclusion criteria were that children were aged 5 to 12 years and had experienced the death of a parent, sibling, or significant relative, at least one month prior to the camp. There was no upper timeframe limit or restrictions as to the means of death. Exclusion criteria included any known significant violence or aggression, significant developmental delay, a history of anti-social behavior in group settings, selfharm, suicidal ideation or risk-taking behavior, or any other factors that may pose a risk to group safety. Children or families already engaged with a psychologist or other therapeutic service were not excluded from participating.

A total of 21 children attended the camp. Pre-test data from 19 children were gathered prior to the group. Six children were lost at post-test and follow-up, and 1 child was not included in the final analysis due to missing data. Data pertaining to 12 children ( 8 girls and 4 boys) were analyzed. A sensitivity analysis revealed that, with an alpha level of .05 , a sample of 12 participants is only capable of capturing a "large" ( $d=0.90)$ effect (Cohen, 1988). Of these 12 children, there were three sets of two siblings; therefore, data was obtained from nine caregiver informants (5 mothers, 2 fathers, 1 grandmother and 1 sister). The mean age of the children was 8.25 years $(S D=2.15)$. All children except one had lost a parent (7 fathers, 4 mothers, and 1 uncle), and the mean time since bereavement was 20.88 months $(S D=23.87)$. Table 1 displays the sample's demographic and loss-related characteristics.

\section{Measures}

Previous studies examining bereavement programs targeting childhood grief have examined environmental, family, and child variables (Lin et al., 2004). For this reason, we used a combination of psychometric measures at pre-test (approximately 2.5 weeks before the camp), post-test (6- 8 weeks after the camp), and follow-up (6 months after the camp). 
Demographic information. At pre-test, caregivers provided demographic information pertaining to the child's age, relationship to the deceased, time since bereavement, and cause of death. Identifying information pertaining to the child such as names, date of birth, address, and school were not collected.

Grief symptomatology. The Inventory of Prolonged Grief for Children (IPG-C; Spuij et al., 2012) is a 30-item child self-report measure that was developed to identify the children's grief symptomatology and was used at pre-test, post-test, and follow-up. The items of the IPG-C are answered on a three-point response scale $(1=$ almost never, $2=$ sometimes, $3=$ always $)$. Internal consistency, temporal stability, concurrent validity, convergent validity, and divergent validity are all adequate in the IPC-C (Spuij et al., 2012), and the authors recommend its use as unidimensional measure. To date, the IPG-C has been validated for use with children as young as 8 years of age. Scores range from 30 to 90, with higher scores indicating higher prolonged grief symptomatology.

Behavioral problems. The Strengths and Difficulties Questionnaire (SDQ; Goodman, 1997) is a brief screening measure of internalizing and externalizing behaviors and psychological attributes and is available in the public domain. The questionnaire has 25 statements with a 3 -point response scale $(0=n o t$ true, $1=$ somewhat true, $2=$ certainly true , and includes five reverse-scored items. The results generate five subscales, each with five items—emotional problems, conduct problems, peer relationship problems, inattention/hyperactivity problems, and prosocial behavior-as well as a total difficulties score. We used the SDQ parent informant for children 4 to 10 years (SDQ P4-10) and parent informant for 11 to 17 years (SDQ P11-17) to compute a total score and scores for the first three subscales. Internal consistency and construct validity of the SDQ subscales is well supported in the literature (He, Bustein, Schmitz, \& Merikangas, 2013), and moderate to strong internal reliability across all subscales has been demonstrated amongst Australian children (Hawes \& Dadds, 2004). Total scores range from 0 to 40, with higher scores indicating more difficulties.

Parenting and family adjustment. The Parenting and Family Adjustment Scales (PAFAS; Sanders, Morawska, Haslam, Filus, \& Fletcher, 2014) is a 30-item parent-report measure of seven dimensions of family functioning (Parental Consistency, Coercive Parenting, Positive Encouragement, 
Parent-Child Relationship, Parental Adjustment, Family Relationships, and Parental Teamwork), which have been supported by confirmatory factor analyses (Mazzucchelli et al., 2018; Sanders et al., 2014). Responses are recorded on a four-point response scale $(0=$ not at all, $1=$ a little, $2=$ quite a lot, $3=$ very much). The PAFAS has adequate convergent validity and internal consistency is good (Sanders et al., 2014). For this study, total scores were calculated for six of the seven dimensions; the Parental Teamwork dimension was omitted from analysis because most of the caregiver participants had lost their parenting partner. Scores range from 0 to 15 for Parental Consistency, Coercive Parenting, Parent-Child Relationship, Parental Adjustment; 0 to 12 for Family Relationships; and 0 to 9 for Positive Encouragement and Parental Teamwork, with higher scores indicating poorer adjustment.

Client satisfaction. At post-test, caregivers were asked to complete a 10-item satisfaction questionnaire adapted from the Client Satisfaction Questionnaire (CSQ; Larsen, Attkisson, Hargreaves, \& Nguyen, 1979). Items related to the caregivers' experience of the camp, and how (if at all) their child's/children's coping has changed compared to prior to the camp. The CSQ comprised closed questions used a 7-point rating scale and an open-ended question ("Do you have any other comments about this service"?) to encourage further comments. Additionally, open-ended questions were included in the post-test child questionnaire to allow children the opportunity to describe their experiences of LHCK.

\section{Procedure}

The study received human research ethics approval from the university's Human Research Ethics Committee. Families were recruited to LHCK via social media and public advertisements, and email distribution of flyers through professional networks. Study participants were recruited by the first author from within those families attending the LHCK camp. The Director of LHCK emailed all enrolled families and advised them of the study objectives, and requested permission to share their contact details with the first author, who then contacted these families via email and telephone. Interested families were provided with child and caregiver information sheets outlining the purpose of the study and participation requirements, and guidelines of how to support participating children. Families also had the opportunity 
to speak with the first author prior to providing informed consent (caregivers) and assent (children). Decisions concerning whether to participate in the study had no bearing on the support provided by LHCK, and the LHCK staff at no point knew which camp attendees participated in the study.

Caregiver participants were emailed the links to complete the measure online, hosted on Qualtrics. Child participants aged 8 to 12 years were also invited to complete their own self-report online questionnaire at the same time. Children aged 5 to 7 years were not asked to complete self-report questionnaires. At each data collection point, the first question required the participant to provide an affirmative response indicating informed consent and the second question required the participant to enter a unique identification number to ensure tracking of scores over time. At pre-test, caregivers completed the demographic questions. At pre-test, post-test, and follow-up, caregivers completed the SDQ and the PAFAS and children aged 8 to 12 years completed the IPG-C. At post-test, caregivers completed the CSQ and children completed open-ended questions.

\section{Data Analysis}

There were 11 outcome measures: (a) Total SDQ score, (b) Emotional problems SDQ subscale, (c) Conduct problems SDQ subscale, (d) Peer problems SDQ subscale; the PAFAS dimensions of (e) Parental Consistency (f) Coercive Parenting, (g) Positive Encouragement, (h) Parent-Child Relationship, (i) Parental Adjustment, and (j) Family Relationships; and (k) Total IPG-C score. A series of Generalized Linear Mixed Models (GLMMs), one for each of the outcome measures, was used to determine whether outcomes changes across time. The GLMMs were implemented through SPSS's (Version 25) GENLINMIXED procedure. The GLMM is an advanced regression model, designed to accommodate markedly non-normal distributions and includes both random and fixed effects. Each of the GLMMs included two nominal random effects (dyad, participant) and one ordinal fixed effect (time), and two covariates (age, time since death).

\section{Results}

Table 2 displays the descriptive statistics of outcome measures for grief symptomatology, behavioral problems, and parenting and family adjustment. 


\section{Grief Symptomatology}

There were no significant changes across the three assessments the IPG-C $(F[2,7]=2.78, p=$ $.129)$.

\section{Behavioral Problems}

There was no significant main effect of time on the total SDQ $(F[2,25]=2.24, p=.128)$. However, there was a significant main effect of time for the SDQ peer problems $(F[2,25]=3.78, p=$ .036) subscale. Post-hoc Least Significant Difference (LSD) tests showed a significant decrease from pretest to post-test $(t[25]=2.33, p=.013)$, indicating that the children's peer relationship problems decreased between these two assessments; no other contrast was significant. There were no significant changes across the three assessments on the SDQ emotional problems $(F[2,25]=1.89, p=.171)$ or SDQ conduct problems $(F[2,25]=3.01, p=.067)$ subscales.

\section{Parenting and Family Adjustment}

There was a significant main effect of time for Parental Consistency $(F[2,24]=4.13, p=.029)$. Post-hoc LSD tests showed a significant improvement from pre-test to follow-up $(t[24]=2.13, p=.044)$. No other contrast was significant. There was a significant main effect of time for Coercive Parenting $(F[2,24]=6.80, p=.005)$. Post-hoc LSD tests showed a significant reduction from pre-test to post-test $(t[24]=3.66, p=.001)$; no other contrast was significant. There was no significant main effect of time for the Positive Encouragement $(F[2,24]=1.47, p=.251)$, Parent-Child Relationship $(F[2,24]=0.40, p=$ .676), Parental Adjustment $(F[2,24]=0.75, p=.484)$, and Family Relationships $(F[2,24]=0.06, p=$ 938) subscales.

\section{Reliable and Clinical Change}

Children's responses on the IPG-C were assessed for reliable change, and caregiver responses on the SDQ and PAFAS were assessed for reliable and clinical change, from pre- to post-intervention (Jacobson \& Truax, 1991; see Table 3). One-third of the participants showed a reliable pre-post improvement in the total SDQ score, half showed a reliable pre-post change improvement in the IPG-C 
score, and none showed a reliably worse pre-post change in their IPG-C score. In all instances, the number of participants in the clinical range post-intervention was less than that at pre-intervention.

\section{Program Satisfaction}

Data obtained from the caregiver CSQ indicated all caregivers provided high ratings of overall satisfaction, quality of service, type and level of help received, extent the camp met their child's needs and their own needs; all also indicated they would recommend the camp to others in a similar situation (Table 4). Caregiver responses to the open-ended questions were consistently favorable (Table 5), indicating the care and commitment from staff and positive outcomes for children and caregivers. There was more variably in the open-ended responses from the children (Table 6), especially concerning the camp activities. The children either reported that the camp had no impact or impacted positively on their lives.

\section{Discussion}

This is the first study to examine the acceptability and effectiveness of LHCK. Results showed that the children's peer relationship problems decreased from pre-test to post-test, parental consistency improved from pre-test to follow-up, and coercive parenting reduced between pre-test to post-test. Additionally, there were trends towards lower grief and improvements in other aspects of family functioning. In particular, there was a trend towards reductions in total SDQ scores across assessments. Although not statistically significant, the reduction from 16.46 at pre-test to 11.42 at follow-up is likely to be of practical significance, given that the pre-test total SDQ mean score was considerably higher than Australian norms for children (10.65 for 7- to 10-year-olds and 8.80 for 11- to 13-year-olds; Mellor, 2005). The acceptability of the service is supported by the caregivers' client satisfaction questionnaire and the caregivers' open-ended responses demonstrating their experience of the service as high quality, wellorganized, and delivered by suitably skilled staff. All caregivers were satisfied with the camp and most of the children's open-ended responses echoed this outcome, suggesting that participating in the camp was associated with positive outcomes for the children and caregivers. Subjective experiences of increased 
coping skills, as well as feelings of social connectedness and hope, are valued evidence of the effectiveness of childhood grief camps (Clute \& Kobayshi, 2013).

LHCK is not an intervention aimed at children with clinical symptoms, and therefore the measures used might not capture the potential holistic benefits of the camp. This is supported by previous research suggesting that grief interventions show greater effectiveness for children showing clinical symptoms compared to children without such symptoms (Currier, Holland, \& Neimeyer, 2007; Rosner, Kruse, \& Hagl, 2010). Notably, the children who described the grief-related activities less favorably were among those in the sample where the most time had passed since bereavement (66 months) and had the lowest IPG-C scores at pre-test. One possible explanation for this finding is that these children have had more time to adapt to the loss than recently-bereaved children, and therefore might not have benefitted as much from the activities. This interpretation is also supported by evidence that children who were bereaved more distally in time show poorer treatment outcomes, possibly due to having already accommodated their losses (Currier et al., 2007).

Strengths of this study include the collection of quantitative and qualitative data from caregivers and children who attended the camp. However, the small number of participants requires caution when interpreting the representativeness of this sample to the wider population of bereaved children and their caregivers. For example, the caregivers in this study were actively seeking support and receptive to it and therefore could be more motivated and/or socially connected than other bereaved families. Research shows that people who are experience greater bereavement distress are less likely to seek professional assistance (Lichtenthal et al., 2011). Additionally, the small sample size also meant that the study was under-powered to detect all but large to very large effects. Six children and their caregivers did not respond to the invitations to complete the post-test and follow-up measures, which reduced the sample size further. The lack of data collection over a longer time period meant we cannot investigate possible sleeper effects, in that the timing of post-test and follow-up measures may have been premature in allowing time for change. Our design prohibits causal determinations of treatment effects (whether 
positive or iatrogenic) but it appears there were no adverse implications for children in attending the camp.

Based on the current findings, we recommend future studies use an experimental design incorporating a wait-list control group to compare differences in grief experience between the intervention and the natural passage of time, or a fully randomized controlled trial comparing LHCK with another intervention. A longer period of data collection, with carefully chosen measures, could also uncover longer-term benefits of the camp. Given the established research base regarding the impact of parental grief on children (Dowrick, \& Lloyd-Williams, 2013; Ellis et al., 2013; Howell et al., 2016; Morris et al., 2016), an adult measure of grief such as the Prolonged Grief-13 (PG-13; Prigerson et al., 2009) could be completed by the caregivers. Interviews could be used to provide insight as to the experiences of the staff and volunteers and the impact of the work on them. Finally, consideration should be given to establishing an upper time limit since bereavement for eligibility for LHCK, such as 2.5 years as used in similar studies (Sandler et al., 2003). Children displaying protracted grief symptoms past this period may be suggestive of a clinical grief presentation, which may require targeted intervention that differs to what is offered by the camp.

In conclusion, most of what we know about grief is not based on children. Many children and their caregivers will adapt to loss but bereavement camps may support this transition and prevent longterm negative outcomes. Lionheart Camp for Kids provides support for bereaved children and their caregivers and might be an important referral option for bereaved children aged 5 to 12 years in Western Australia. Our findings show that the camp may reduce the children's overall behavioral problems, promote parental consistency, lessen coercive parenting, and there was a trend towards lower selfreported grief for the children. Additionally, the caregivers were highly satisfied and the children reported feeling better. In determining the camp's effectiveness, thought must be given to considering the constructs to measure and the utility of a wait-list or randomized controlled trial design over a longer time period. 


\section{Acknowledgements}

We offer our sincerest gratitude to the bereaved adults and children who so generously gave of their time and experiences to participate in this research, and without whom this project would not have been possible. We thank Lionheart Camp for Kids. Lionheart Camp for Kids had no role in the design of the study or in the analysis and interpretation of data. 


\section{References}

American Academy of Pediatrics Section on Hospice and Palliative Medicine and Committee on Hospital Care. (2013). Pediatric palliative care and hospice care commitments, guidelines, and recommendations. Pediatrics, 132, 966-972.

Aynsley-Green, A., Penny, A., \& Richardson, S. (2012). Bereavement in childhood: Risks, consequences and responses. BMJ Supportive and Palliative Care, 2(1), 2-4.

Bergman, A.-S., Axberg, U., \& Hanson, E. (2017). When a parent dies - a systematic review of the effects of support programs for parentally bereaved children and their caregivers. BMC Palliative Care, 16. doi:10.1186/s12904-017-0223-y.

Breen, L. J., Aoun, S. M., O'Connor, M., \& Rumbold, B. (2014). Bridging the gap in palliative care bereavement support: An international perspective. Death Studies, 38, 54-61.

Breen, L. J., Szylit, R., Gilbert, K. R., Macpherson, C., Murphy, I., Nadeau, J. W., Reis e Silva, D., Wiegand, D. L., \& the International Work Group on Death, Dying, and Bereavement (2019). Invitation to grief in the family context. Death Studies, 43, 173-182.

Brent, D., Melhem, N., Donohoe, M. B., \& Walker, M. (2009). The incidence and course of depression in bereaved youth 21 months after the loss of a parent to suicide, accident, or sudden natural death. The American Journal of Psychiatry, 166, 786-794.

Carr, A. (2015). The handbook of child and adolescent clinical psychology: A contextual approach (3rd ed). London, England: Routledge.

Christ, G. H., \& Christ, A. E. (2006). Current approaches to helping children cope with a parent's terminal illness. A Cancer Journal for Clinicians, 56, 197-212.

Cohen, J. (1988). Statistical power analysis for the behavioral sciences (2nd ed.). Hillsdale, NJ: Erlbaum. Clute, M., \& Kobayshi, R. (2013). Are children's grief camps effective? Journal of Social Work in EndOf-Life and Palliative Care, 9, 43-57. 
Currier, J. M., Holland, J. M., Neimeyer, R. A. (2007). The effectiveness of bereavement interventions with children: A meta-analytic review of controlled outcome research. Journal of Clinical Child and Adolescent Psychology, 36, 253-259.

Ellis, J., Dowrick, C., \& Lloyd-Williams, M. (2013). The long-term impact of early parental death: Lessons from a narrative study. Journal of the Royal Society of Medicine, 106, 67-67.

Fletcher, J., Mailick, M., Song, J., \& Wolfe, B. (2013). A sibling death in the family: Common and consequential. Demography, 50, 803-826.

Fletcher, J., Vidal-Fernandez, M., \& Wolfe, B. (2018). Dynamic and heterogeneous effects of sibling death on children's outcomes. Proceedings of the National Academy of Sciences of the United States of America, 115, 115-120.

Goodman, R. (1997). The strengths and difficulties questionnaire: A research note. Journal of Child Psychology and Psychiatry, 38, 581-586.

Griese, B., Burns, M. R., Farro, S. A., Silvern, L., \& Talmi, A. (2017). Comprehensive grief care for children and families: Policy and practice implications. American Journal of Orthopsychiatry, 87, $540-548$.

Hawes, D., \& Dadds, M. (2004). Australian data and psychometric properties of the Strengths and Difficulties Questionnaire. Australian and New Zealand Journal of Psychiatry, 38, 644-51.

He, J., Burstein, M., Schmitz, A., Merikangas, K. (2013). The Strengths and Difficulties Questionnaire (SDQ): The factor structure and scale validation in U.S. adolescents. Journal of Abnormal Child Psychology, 41, 583-95.

Howell, K. H., Barrett-Becker, E. P., Burnside, A. N., Wamser-Nanney, R., Layne, C. M., \& Kaplow, J. B. (2016). Children facing parental cancer versus parental death: The buffering effect of positive parenting and emotional expression. Journal of Child and Family Studies, 25, 152-164.

Hulsey, E. G., Hill, R. M., Layne, C. M., Gaffney, D. A., \& Kaplow, J. B. (2018). Calculating the incidence rate of sibling bereavement among children and adolescence across the United States: 
A proposed method. Death Studies, advance online publication.

doi:10.1080/07481187.2018.1541946

Jacobson N., \& Truax, P. (1991). Clinical significance: A statistical approach to defining meaningful change in psychotherapy-research. Journal of Consulting and Clinical Psychology, 59, 12-19.

Kirwin, K., \& Hamrin, V. (2005). Decreasing the risk of complicated bereavement and future psychiatric disorders in children. Journal of Child and Adolescent Psychiatric Nursing, 18, 62-78.

Larsen, D. L., Attkisson, C., Hargreaves, W., \& Nguyen, T. D. (1979). Assessment of client/patient satisfaction: Development of a general scale. Evaluation and Program Planning, 2, 197-207.

Lichtenthal, W. G., Nilsson, M., Kissane, D. W., Breitbart, W., Kacel, E., Jones, E. C., \& Prigerson, H. G. (2011). Underutilization of mental health services among bereaved caregivers with prolonged grief disorder. Psychiatric Services, 62, 1225-1229.

Lin, K. K., Irwin, N., Sandler, T. S., Ayers, S. A., \& Wolchik, S. A., \& Luecken, L. J. (2004). Resilience in parentally bereaved children and adolescents seeking preventive services. Journal of Clinical Child and Adolescent Psychology, 33, 673-683.

Machajewski, V., \& Kronk, R. (2013). Childhood grief related to the death of a sibling. The Journal for Nurse Practitioners, 9, 443-448.

Mazzucchelli, T. G., Hodges, J., Kane, R. T., Sofronoff, K., Sanders, M. R., Einfeld, S., . . Gray, K. M. (2018). Parenting and family adjustment scales (PAFAS): Validation of a brief parent-report measure for use with families who have a child with a developmental disability. Research in Developmental Disabilities, 72, 140-151.

Melhem, N. M., Moritz, M. P. H., Walker, M. S. W., Shear, M. K., \& Brent, D. (2007). Phenomenology and correlates of complicated grief in children and adolescents. Journal of American Academy of Child and Adolescent Psychology, 46, 493-499.

Mellor, D. (2005). Normative data for the Strengths and Difficulties Questionnaire in Australia. Australian Psychologist, 40, 215-222. 
Morris, A. T., Gabert-Quillen, C., Friebert, S., Carst, N., \& Dalahunty, D. L. (2016). The indirect effect of positive parenting on the relationship between parent and sibling bereavement outcomes after the death of a child. Journal of Pain and Symptom Management, 51, 60-70.

Owens, D. A. (2008). Recognizing the needs of bereaved children in palliative care. Journal of Hospice and Palliative Nursing, 10(1), 14-16.

Parsons, S. (2011). Long-term impact of childhood bereavement: Preliminary analysis of the 1970 British Cohort Study (BCS70). London, England: Childhood Wellbeing Research Centre.

Pfeffer, C. R., Karus, D., Siegel, K., Jiang, H. (2000). Child survivors of parental death from cancer or suicide: Depressive and behavioural outcomes. Psycho-oncology, 9, 1-10.

Prigerson, H. G., Horowitz, M. J., Jacobs, S. C., Parkes, C. M., Aslan, M., Goodkin, K., ... Maciejewski, P. K. (2009). Prolonged grief disorder: Psychometric validation of criteria proposed for DSM-V and ICD-11. PLoS Medicine, 6. doi:10.1371/journal.pmed.1000121

Ribbens McCarthy, J., \& Jessop, J. (2005). Young people, bereavement and loss: Disruptive transitions? London: England: National Children's Bureau for the Joseph Rowntree Foundation.

Rolls, L., \& Penny, A. (2011). Mapping evaluation of UK childhood bereavement services. Bereavement Care, 30, 300-328.

Rosner, R., Kruse, J., Hagl, M. (2010). A meta-analysis of interventions for bereaved children and adolescents. Death Studies, 34, 99-136.

Saldinger, A., Porterfield, K., \& Cain, A. C. (2004). Meeting the needs of parentally bereaved children: A framework for child-centred parenting. Psychiatry, 67, 331-352.

Sanders, M. R., Morawska, A., Haslam, D. M., Filus, A., Fletcher, R. (2014). Parenting and family adjustment scales (PAFAS): Validation of a brief parent-report measure for use in assessment of parenting skills and family relationships. Child Psychiatry Human Development, 45, 255-272.

Sandler, I. N., Ayers, T. S., Wolchik, S. A., Tein, J. Y., Kwok, O. M., Haine, R. A., ... \& Weyer, J. L. (2003). The Family Bereavement Program: Efficacy evaluation of a theory-based prevention 
program for parentally bereaved children and adolescents. Journal of Consulting and Clinical Psychology, 71, 587-600.

Sandler, I., Tein, J.-Y., Cham, H., Wolchik, S., \& Ayers, T. (2016). Long-term effects of the Family Bereavement Program on spousal bereaved parents: Grief, mental health problems, alcohol problems, and coping efficacy. Development and Psychopathology, 28, 801-818.

Spuij, M., Prinzie, P., Zijderlaan, J., Stikkelbroek, Y., Dillen, L., de Roos, C., Boelen, P. A. (2012). Psychometric properties of the Dutch Inventories of Prolonged Grief for Children and Adolescents. Clinical Psychology and Psychotherapy, 19, 540-551.

Tafà, M., Cerniglia, L., Cimino, S., Ballarotto, G., Marzilli, E., \& Tambelli, R. (2018). Predictive values of early parental loss and psychopathological risk for physical problems in early adolescents. Frontiers in Psychology, 9, article 922. doi:10.3389/fpsyg.2018.00922

Wilson, D. M., Dhanji, N., Playfair, R., Nayak, S. S., Puplampu, G. L., \& MacLeod, R. (2017). A scoping review of bereavement service outcomes. Palliative and Supportive Care, 15, 242-259.

Worden, J. W., \& Silverman, P. R. (1996). Parental death and the adjustment of school-age children. Omega: Journal of Death and Dying, 35, 91-102. 
Table 1

Demographic Characteristics of Child Participants

\begin{tabular}{cccccc}
\hline $\begin{array}{c}\text { Age of } \\
\text { child } \\
\text { (years) }\end{array}$ & Gender & $\begin{array}{c}\text { Relationship of } \\
\text { caregiver informant } \\
\text { to child }\end{array}$ & $\begin{array}{c}\text { Relationship } \\
\text { of deceased } \\
\text { to child }\end{array}$ & $\begin{array}{c}\text { Time since } \\
\text { bereavement }\end{array}$ & Cause of death \\
\hline 8 & Male & Grandmother & Mother & 42 months & Accidental sudden death \\
10 & Female & Father & Mother & 66 months & Illness \\
10 & Male & Father & Mother & 66 months & Illness \\
9 & Female & Mother & Father & 3 months & Illness \\
11 & Female & Mother & Father & 3 months & Illness \\
8 & Male & Mother & Father & 3 months & Motor vehicle crash \\
6 & Female & Mother & Father & 3 months & Motor vehicle crash \\
7 & Female & Sister & Father & 36 months & Suicide \\
5 & Female & Father & Mother & 1.5 months & Illness \\
6 & Female & Mother & Father & 11 months & Other \\
7 & Female & Mother & Father & 10 months & Heart attack \\
12 & Male & Mother & Uncle & 6 months & Heart attack \\
\hline
\end{tabular}


Table 2

Descriptive Statistics for Outcome Measures

\begin{tabular}{|c|c|c|c|c|c|c|}
\hline \multirow[t]{2}{*}{ Measures } & \multicolumn{2}{|c|}{ Pre-test } & \multicolumn{2}{|c|}{ Post-test } & \multicolumn{2}{|c|}{ Follow-up } \\
\hline & Mean $(S E)$ & $95 \% \mathrm{CI}$ & Mean $(S E)$ & $95 \% \mathrm{CI}$ & Mean $(S E)$ & $95 \% \mathrm{CI}$ \\
\hline \multicolumn{7}{|l|}{ SDQ } \\
\hline Total score & $16.46(2.15)$ & $12.02-20.89]$ & $15.87(2.51)$ & [10.71-21.03] & $11.42(2.94)$ & [5.38-17.47] \\
\hline Emotional problems & $4.64(0.69)$ & {$[3.21-6.01]$} & $3.97(0.75)$ & $[2.42-5.52]]$ & $3.43(1.16)$ & {$[1.03-5.82]$} \\
\hline Conduct problems & $3.26(0.77)$ & {$[1.68-4.84]$} & $3.26(0.77)$ & {$[1.67-4.85]$} & $2.34(0.72)$ & {$[0.84-3.82]$} \\
\hline Peer problems & $2.96(0.51)^{*}$ & $1.90-4.02]$ & $2.63(0.72)$ & [1.14-4.11] & $1.65(0.68)^{*}$ & $0.25-3.06]$ \\
\hline \multicolumn{7}{|l|}{ PAFAS } \\
\hline Parental consistency & $5.65(0.59)^{*}$ & $4.43-6.87]$ & $4.66(0.62)$ & {$[3.37-5.94]$} & $4.20(0.61)^{*}$ & {$[2.95-5.46]$} \\
\hline Coercive parenting & $5.43(0.87)^{*}$ & {$[3.56-7.13]$} & $3.97(0.76)^{*}$ & {$[2.41-5.54]$} & $4.33(0.66)$ & {$[2.97-5.70]$} \\
\hline Positive encouragement & $2.77(0.45)$ & {$[1.85-3.69]$} & $2.04(0.41)$ & {$[1.20-2.88]$} & $2.50(0.29)$ & {$[1.90-3.10]$} \\
\hline Parent-child relationship & $1.26(0.55)$ & [0.12-2.39] & $1.36(0.77)$ & {$[-0.24-2.95]$} & $1.08(0.54)$ & {$[-0.04-2.20]$} \\
\hline Parental adjustment & $7.89(0.73)$ & {$[6.34-9.39]$} & $7.25(0.54)$ & {$[6.14-8.35]$} & $6.92(1.03)$ & {$[4.78-9.06]$} \\
\hline Family relationships & $3.05(0.64)$ & {$[1.72-4.38]$} & $3.00(0.57)$ & [1.81-4.19] & $2.98(0.53)$ & {$[1.89-4.08]$} \\
\hline IPG-C & $57.63(2.42)$ & [54.64-60.61] & $53.89(4.36)$ & [43.60-64.18] & $54.46(2.42)$ & [48.73-60.18] \\
\hline
\end{tabular}

Note. *indicates significant difference. $S E=$ standard error of the mean, $\mathrm{CI}=$ confidence interval, SDQ = Strengths and Difficulties Questionnaire, PAFAS = Parenting and Family Adjustment Scales, IPG-C = Inventory for Prolonged Grief-Children. 
Table 3

Pre-Post Reliable Change Indices and Clinical Change

\begin{tabular}{|c|c|c|c|c|}
\hline \multirow[t]{2}{*}{ Measure } & \multirow{2}{*}{$\begin{array}{c}\text { Reliably Improved } \\
\qquad \%(n / N)\end{array}$} & \multirow{2}{*}{$\begin{array}{l}\text { Reliably Worse } \\
\qquad \%(n / N)\end{array}$} & \multirow{2}{*}{$\begin{array}{c}\text { Clinical Range Pre- } \\
\text { intervention } \\
\%(n / N)\end{array}$} & \multirow{2}{*}{$\begin{array}{c}\text { Clinical Range Post- } \\
\text { intervention } \\
\%(n / N)\end{array}$} \\
\hline & & & & \\
\hline \multicolumn{5}{|l|}{ SDQ } \\
\hline Total score & $33.3 \%(4 / 12)$ & $8.3 \%(1 / 12)$ & $50.0 \%(6 / 12)$ & $33.3 \%(4 / 12)$ \\
\hline Emotional problems & $16.7 \%(2 / 12)$ & $8.3 \%(1 / 12)$ & $50.0 \%(6 / 12)$ & $41.7 \%(5 / 12)$ \\
\hline Conduct problems & $8.3 \%(1 / 12)$ & $8.3 \%(1 / 12)$ & $41.7 \%(5 / 12)$ & $25 \%(3 / 12)$ \\
\hline Peer problems & $16.7 \%(2 / 12)$ & $16.7 \%(2 / 12)$ & $33.3 \%(4 / 12)$ & $25.0 \%(3 / 12)$ \\
\hline \multicolumn{5}{|l|}{ PAFAS } \\
\hline Parental consistency & $9.1 \%(1 / 11)$ & $0.0 \%(0 / 11)$ & $58.3 \%(7 / 12)$ & $36.4 \%(4 / 11)$ \\
\hline Coercive parenting & $0.0 \%(0 / 11)$ & $0.0 \%(0 / 11)$ & $16.7 \%(2 / 12)$ & $9.1 \%(1 / 11)$ \\
\hline Positive encouragement & $27.3 \%(3 / 11)$ & $9.1 \%(1 / 11)$ & $33.3 \%(4 / 12)$ & $9.1 \%(1 / 11)$ \\
\hline Parent-child relationship & $9.1 \%(1 / 11)$ & $9.1 \%(1 / 11)$ & $16.7 \%(2 / 12)$ & $9.1 \%(1 / 11)$ \\
\hline Parental adjustment & $18.2 \%(2 / 11)$ & $9.1 \%(1 / 11)$ & $50.0 \%(6 / 12)$ & $45.4 \%(5 / 11)$ \\
\hline Family relationships & $0.0 \%(0 / 11)$ & $0.0 \%(0 / 11)$ & $25.0 \%(3 / 12)$ & $18.2 \%(2 / 11)$ \\
\hline \multicolumn{5}{|l|}{ IPG-C } \\
\hline Total & $50.0 \%(2 / 4)$ & $0.0 \%(0 / 4)$ & & \\
\hline
\end{tabular}

Note. IPG-C = Inventory for Prolonged Grief-Children, PAFAS = Parenting and Family Adjustment Scales, SDQ = Strengths and Difficulties Questionnaire. 
Table 4

Caregiver Satisfaction Questionnaire for Lionheart Camp for Kids

\begin{tabular}{|c|c|c|}
\hline Question & $\begin{array}{l}\text { Satisfaction } \\
\text { Mean }(S D)\end{array}$ & $\begin{array}{c}\text { Satisfied to very } \\
\text { satisfied } \\
\%(N)\end{array}$ \\
\hline $\begin{array}{l}\text { 1. How would you rate the quality of the service you and your } \\
\text { child received? }\end{array}$ & $6.92(0.08)$ & $100(12)$ \\
\hline $\begin{array}{l}\text { 2. Did you receive the type of help you wanted from this } \\
\text { service? }\end{array}$ & $6.17(0.64)$ & $100(12)$ \\
\hline 3. To what extent has this service met your child's needs? & $5.42(0.41)$ & $100(12)$ \\
\hline 4. To what extent has this service met your needs? & $5.75(0.52)$ & $100(12)$ \\
\hline $\begin{array}{l}\text { 5. How satisfied were you with the level of help you and your } \\
\text { child received? }\end{array}$ & $6.42(0.37)$ & $100(12)$ \\
\hline $\begin{array}{l}\text { 6. Has this service helped you to deal more effectively with } \\
\text { your child's grief? }\end{array}$ & $5.58(1.41)$ & $75.0(9)$ \\
\hline $\begin{array}{l}\text { 7. In an overall sense, how satisfied are you with the service } \\
\text { you and your child received? }\end{array}$ & $6.42(0.57)$ & $100(12)$ \\
\hline $\begin{array}{l}\text { 8. If a friend were in need of similar help, would you } \\
\text { recommend this service? }\end{array}$ & $6.92(0.08)$ & $100(12)$ \\
\hline 9. In your opinion, how is your child's coping at this point? & $5.25(0.85)$ & $83.3(10)$ \\
\hline $\begin{array}{l}\text { 10. How would you describe your feelings at this point about } \\
\text { your child's progress? }\end{array}$ & $5.42(1.08)$ & $66.6(8)$ \\
\hline
\end{tabular}

Note. 1 = very satisfied, 7 = very dissatisfied. 
Table 5

Caregiver Open-ended Responses

Brilliant program run by amazing people. [Director] and team were phenomenal. I tell anyone and everyone about this service.

Very well organized and generally beneficial to me and my children.

Lionhearted has been great for my child. It has freed him from a lot of his anger and heartache and restore [sic] his sense of self.

I've contacted [Director] directly and expressed my gratitude.

An excellent service from committed caring people.

This is a great service for grieving families.

Lionheart is an excellent program for both adults and children.

Wonderful service!

A wonderful service that helps make us parents feel less alone. 
Table 6

Children's Open-ended Prompts and Responses

\begin{tabular}{|c|c|}
\hline Prompts & Responses \\
\hline $\begin{array}{l}\text { The day before Lionheart I } \\
\text { felt... }\end{array}$ & $\begin{array}{l}\text { Average. } \\
\text { I didn't want to go and I felt nervous. } \\
\text { A bit excited. } \\
\text { Excited and scared. }\end{array}$ \\
\hline At Lionheart I liked.... & $\begin{array}{l}\text { The food. } \\
\text { I liked making things and friends. } \\
\text { Shaking the glass around with colors mixing together. } \\
\text { The sand thing. }\end{array}$ \\
\hline At Lionheart I did not like... & $\begin{array}{l}\text { The activities. } \\
\text { Talking about my mum all the time. } \\
\text { Leaving. I really liked it there. } \\
\text { There was nothing I did not like. }\end{array}$ \\
\hline $\begin{array}{l}\text { If I knew another child who } \\
\text { had someone important in } \\
\text { their lives die I tell them these } \\
\text { things... }\end{array}$ & $\begin{array}{l}\text { You're not the only one that has had something like that happen. } \\
\text { About my mum, my worries, and fears. } \\
\text { It's really hard because I felt confused, sad, and angry. } \\
\text { I don't know. }\end{array}$ \\
\hline $\begin{array}{l}\text { When I went to school after } \\
\text { Lionheart... }\end{array}$ & $\begin{array}{l}\text { Happy. } \\
\text { We went to a new school. I was excited and nervous. I've only told } 2 \\
\text { new friends that my dad died. I'll tell people when I'm ready. } \\
\text { I felt better. }\end{array}$ \\
\hline $\begin{array}{l}\text { Since Lionheart these things } \\
\text { have changed... }\end{array}$ & $\begin{array}{l}\text { Nothing. } \\
\text { We changed school and where we live. I fall asleep quicker at night. } \\
\text { I'm happier. } \\
\text { My feelings and heart. }\end{array}$ \\
\hline $\begin{array}{l}\text { Lionheart next time why don't } \\
\text { you... }\end{array}$ & $\begin{array}{l}\text { Play with paper bombs and throw them around the room. If you get } \\
\text { hit, you have to freeze, then someone has to tag you to unfreeze you. } \\
\text { Teach us about the body as in how it dies. }\end{array}$ \\
\hline
\end{tabular}

